\title{
Poética da cidade em Carlos Drummond de Andrade (Brejo das Almas)
}

\author{
Felipe Cabañas da Silva ${ }^{1}$
}

Resumo: Este artigo se insere nos estudos que relacionam geografia e literatura e tem como objetivo analisar a segunda obra de poemas de Carlos Drummond de Andrade, "Brejo das Almas", publicada em 1934, sob a ótica da vivência urbana na modernidade. Para tanto, analisamos as características geográficas da cidade de Brejo das Almas (atualmente Francisco Sá) por meio dos dados de recenseamento e confrontamos sua realidade objetiva com a expressão subjetiva do autor. Buscamos, assim, ir além do conceito de representação, que se limita a uma compilação ou descrição do espaço contido na obra. Procuramos lançar, desta maneira, um olhar "geo-literário" sobre o interior mineiro a partir da obra de Drummond, entendendo a obra literária e o espaço geográfico como uma totalidade. Encontramos na poesia de Drummond sobre o interior de Minas a força das contradições da modernidade e em Brejo das Almas o mote de uma expressão poética que integra o espaço urbano como dimensão da existência.

Palavras-chave: Drummond; Brejo das Almas; modernidade; cidade; geografia; literatura.

\section{Poética de la ciudad en Carlos Drummond de Andrade (Brejo das Almas)}

Resumen: Este artículo es parte de los estudios que relacionan geografía y literatura y tiene como objetivo analizar la segunda obra de poemas de Carlos Drummond de Andrade, "Brejo das Almas", publicada en 1934, desde la perspectiva de la vida urbana en la modernidad. Para tanto, analizamos las características geográficas de la ciudad de Brejo das Almas (actualmente Francisco Sá), utilizando los datos del censo y comparamos su realidad objetiva con la expresión subjetiva del autor. Por lo tanto, buscamos ir más allá del concepto de representación, que se limita a una compilación o descripción del espacio contenido en la obra. De esta manera, buscamos una mirada "geo-literaria" al interior de Minas Gerais basada en el trabajo de Drummond, entendiendo el trabajo literario y el espacio geográfico en su conjunto. Encontramos en la poesía de Drummond sobre el interior de Minas la fuerza de las contradicciones de la modernidad y en Brejo das Almas el lema de una expresión poética que integra el espacio urbano como una dimensión de la existencia.

Palabras-claves: Drummond; Brejo das Almas; modernidad; ciudad; geografía; literatura.

\section{City poetics in Carlos Drummond de Andrade (Brejo das Almas)}

\begin{abstract}
This article is part of the studies that relate geography and literature and aims to analyze the book "Brejo das Almas", published in 1934 by Carlos Drummond de Andrade, from the perspective of urban living in modernity. To do so, we analyzed the geographical characteristics of the city of Brejo das Almas (currently Francisco Sá), using the census data and comparing its objective reality with the subjective expression of the author. Thus, we seek to go beyond the concept of representation, which is limited to a compilation or description of the space contained in literature. In this way, we seek to take a "geo-literary" look at the interior of Minas Gerais based on Drummond's work, understanding the literary work and the geographical space as a whole. We find in Drummond's poetry about the interior of Minas the strength of the contradictions of modernity and in Brejo das Almas the motto of a poetic expression that integrates urban space as a dimension of the existence.

Keywords: Drummond; Brejo das Almas; modernity; city; geography; literature.
\end{abstract}

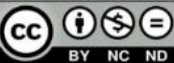

DOI: https://doi.org/10.26512/patryter.v4i8.31245

Como citar este artigo: Silva, F. C. (2021). Poética da cidade em Carlos Drummond de Andrade (Brejo das Almas). PatryTer - Revista Latinoamericana e Caribenha de Geografia e Humanidades, 4(8), 107-122. DOI: https://doi.org/10.26512/patryter.v4i8.31245

Recebido: 29 de abril de 2020. Aceite: 05 de setembro de 2020. Publicado: 01 de setembro de 2021 .

${ }^{1}$ Doutor em Geografia Humana pela Universidade de São Paulo - USP. ORCID: https:/ /orcid.org/0000-0002-2364-

7486. E-mail: fecdasilva@yahoo.com.br. 


\section{Introdução}

Geografia e literatura têm estreitado cada vez mais os seus laços nas últimas décadas e o diálogo entre geógrafos, escritores e críticos literários se torna cada vez mais produtivo. Capaz de (re)significar o espaço e a geografia, a literatura se consolida como objeto de uma disciplina de "longa tradição conservadora" (Corrêa, 1980, p. 8), em que o positivismo fez escola e preconizou a objetividade na análise dos sujeitos sociais.

No esteio da sua renovação crítica, a partir da década de 1970, a geografia se abre para novos universos e novas perspectivas. Neste momento, ganha força uma corrente radical, inspirada sobretudo pelo marxismo, e uma corrente humanística, inspirada sobretudo pela fenomenologia. Ambas comungam da crítica à geografia neopositivista e do interesse pela subjetividade - interesse que ganha contornos muito diferentes segundo a corrente, evidentemente.

Aqui, abre-se um claro caminho para o diálogo com a arte, um conjunto de linguagens que expressa a subjetividade e a relação do sujeito com o espaço. Compreende-se, assim, a literatura no panteão das artes, como forma criativa que dá voz à subjetividade social e manifesta através dessa voz um inconsciente coletivo. Esse diálogo se fortalece nas últimas décadas, mas Brosseau (1996) e Lévy (2006) demonstram que ele é mais antigo. Lévy (2006) vai encontra-lo já na Grécia antiga, momento que não conhece a rígida divisão do saber da modernidade.

Não obstante esse estreitamento de laços e a riqueza das "pesquisas geo-literárias" ii (Lévy, 1997, p. 29) na atualidade, também nos deparamos com alguns limites. Brosseau (1996), por exemplo, demonstra que a geografia privilegia o romance em suas análises, especialmente o realista, cujo discurso se aproxima do discurso científico. Lafaille (1989), por sua vez, aponta a dificuldade da geografia para dialogar com a literatura moderna, onde a forma literária se desconstrói:

Submetida a preconceitos humanistas e românticos,
a geografia não vê no texto literário mais que um
reservatório de imagens geográficas. Semelhante
abordagem impõe sérios limites à análise literária
em geografia; ela impede, no minimo, toda relacaão
com o texto poético moderno. A partir das
Iluminacooes, de Rimbaud, primeira manifestacão
do nonsense na literatura ocidental, ficou
comprovado que o que é essencial nesta poesia não é
a experiência original da cidade que ela apresenta, mas a transformação radical da função textual que ela opera. Consequentemente, o geógrafo é levado a questionar sua relação com os textos (...). À parte poucas excę̧ões, os geógrafos confundem a literatura com um meio de informação, com um catálogo de paisagens geográficas, com um documento capaz de esclarecer as atitudes e os valores dos homens $e$ mulberes que babitam o mundo, em suma a literatura é tratada como uma fonte de dadosiii (Lafaille, 1989, p. 118).

Marinho (2010) tem percepção semelhante. Para ele, parte expressiva da pesquisa geo-literária está calcada no estudo puro das representações do espaço, seguindo o "antigo projeto schopenhaueriano do mundo como representação, aquele que afirma unidirecionalmente que tudo o que existe no mundo está para o sujeito que o idealiza" (Marinho, 2010, pp. 12-13). Essa centralização em torno do conceito de representação faz com que a geografia frequentemente não veja na literatura mais que um repositório de informações geográficas a serem catalogadas ou utilizadas para enriquecer a compreensão da região ou do lugar.

Neste artigo, pretendemos desafiar esses limites, buscando, simultaneamente, efetuar uma aproximação entre o pensamento geográfico e a poesia moderna e ir além do simples apontamento das representações do espaço. Nosso enfoque é o segundo livro de poemas de Carlos Drummond de Andrade, publicado em 1934 com o título da cidade mineira de "Brejo das Almas", atualmente Francisco Sá. Pretendemos refletir sobre a relação do homem com a cidade, bem como sobre o papel que a linguagem poética pode desempenhar na expressão e na (re)construção dessa relação.

Compreendemos, aqui, o urbano como "fenômeno espacial de dimensões existenciais" (Scarlato \& Costa, 2017, p. 2), e entendemos que na literatura se realiza a concreção entre as dimensões objetiva e subjetiva da existência, assim como ocorre no espaço urbano: "O que se toma por natureza e sentido do urbano apreende-se pelo fato cidade em sua objetivação e subjetivação, prenha de contradições" (Scarlato \& Costa, 2017, p. 12).

Desta maneira, compreendendo a cidade como "fenômeno espacial de dimensões existenciais", reconhecemos a importância da subjetividade, que tem uma dimensão corpórea e sentimental. O sujeito é corpo e sentimento, e elemento central na produção e reprodução da cidade, através de suas práticas sociais. Neste sentido, "a produção e reprodução das cidades é 
resultado da obra constante de seus habitantes" e, por isso, "a análise das práticas e seus significados é incompleta se não se consideram as emoções e a afetividade"iv (Lindón, 2009, pp. 11-12).

A poesia, neste sentido, formaliza uma leitura da cidade que parte do sujeito histórico concreto, ser poético e urbano, "sujeito-corpo" e "sujeito-sentimento" v (Lindón, 2009), revelando aspectos subjacentes à realidade social que a sensibilidade poética capta e (re)significa. Além do mais, ela é testemunho do sujeito em sua corporeidade/sentimentalidade, revelando suas práticas sociais na/da cidade. A arte, em geral, e a literatura, em particular, se tornam, a partir desta concepção, instrumentos de compreensão/intervenção na cidade, como buscaremos demonstrar através da leitura crítica do nosso "maior poeta social" (Cândido, 2011, p. 85), Carlos Drummond de Andrade.

\section{De Brejo das Almas a Francisco Sá: o município}

Brejo das Almas, hoje Francisco Sá, é uma pequena cidade do norte de Minas Gerais, a aproximadamente $500 \mathrm{~km}$ da capital, Belo Horizonte. O nome curioso de Brejo das Almas vigorou entre 1923 e 1938 (IBGE, 2017), tempo suficiente para dar título ao segundo livro de Carlos Drummond de Andrade, em 1934. A seguir, situamos o município no mapa de Minas, junto a outras cidades marcantes na "obra-vida" de Drummond, que integram o poema "Lanterna Mágica", publicado no primeiro livro do poeta, "Alguma Poesia", em 1930.

Brejo das Almas foi, primeiramente, um distrito de Montes Claros, elevado à categoria de município pela Lei Estadual no 843, de 07-09-1923, dia da comemoração da independência do Brasil. Em 1938, passa a chamar-se Francisco Sá por força do Decreto-lei Estadual no 148, de 17 de dezembro. Hoje, o município é constituído por três distritos: Francisco Sá, Canabrava e Catuni, possui população de aproximadamente 26 mil pessoas e densidade demográfica de $9,07 \mathrm{hab} / \mathrm{km}^{2}$. É cidade pouco desenvolvida, onde a remuneração média mensal dos trabalhadores formais é de aproximadamente 1,7 salários mínimos, o que a situa na posição de número 3666 de 5570 municípios brasileiros e 362 de 853 municípios mineiros. O PIB per capita é baixo, $\mathrm{R} \$ 11.411,27$, posição de número 3386 no país e 473 em Minas. Pelo censo de 2010, o esgotamento sanitário adequado só chega a 46,1\% das residências e a urbanização de vias públicas não ultrapassa $0,3 \%$.

Figura 1 - As cidades do poema "Lanterna Mágica” (1930), além de Brejo das Almas (Francisco Sá)

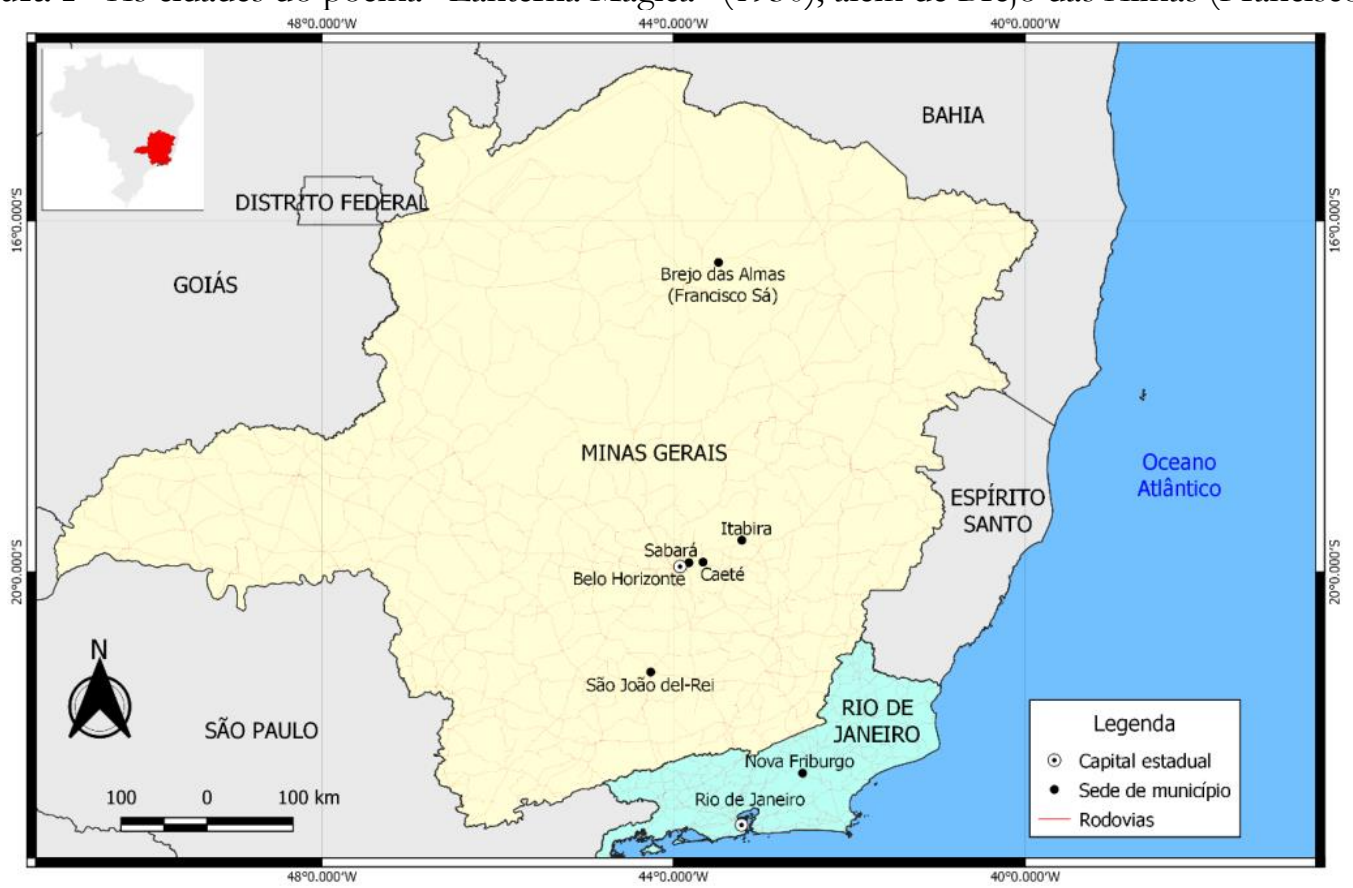

Fonte: elaboração própria, 2019, a partir de IBGE (2017) e

Sistema de Coordenadas Geográficas: Datum SIRGAS 2000. 
Figura 2 - Desigualdade de renda em Minas Gerais

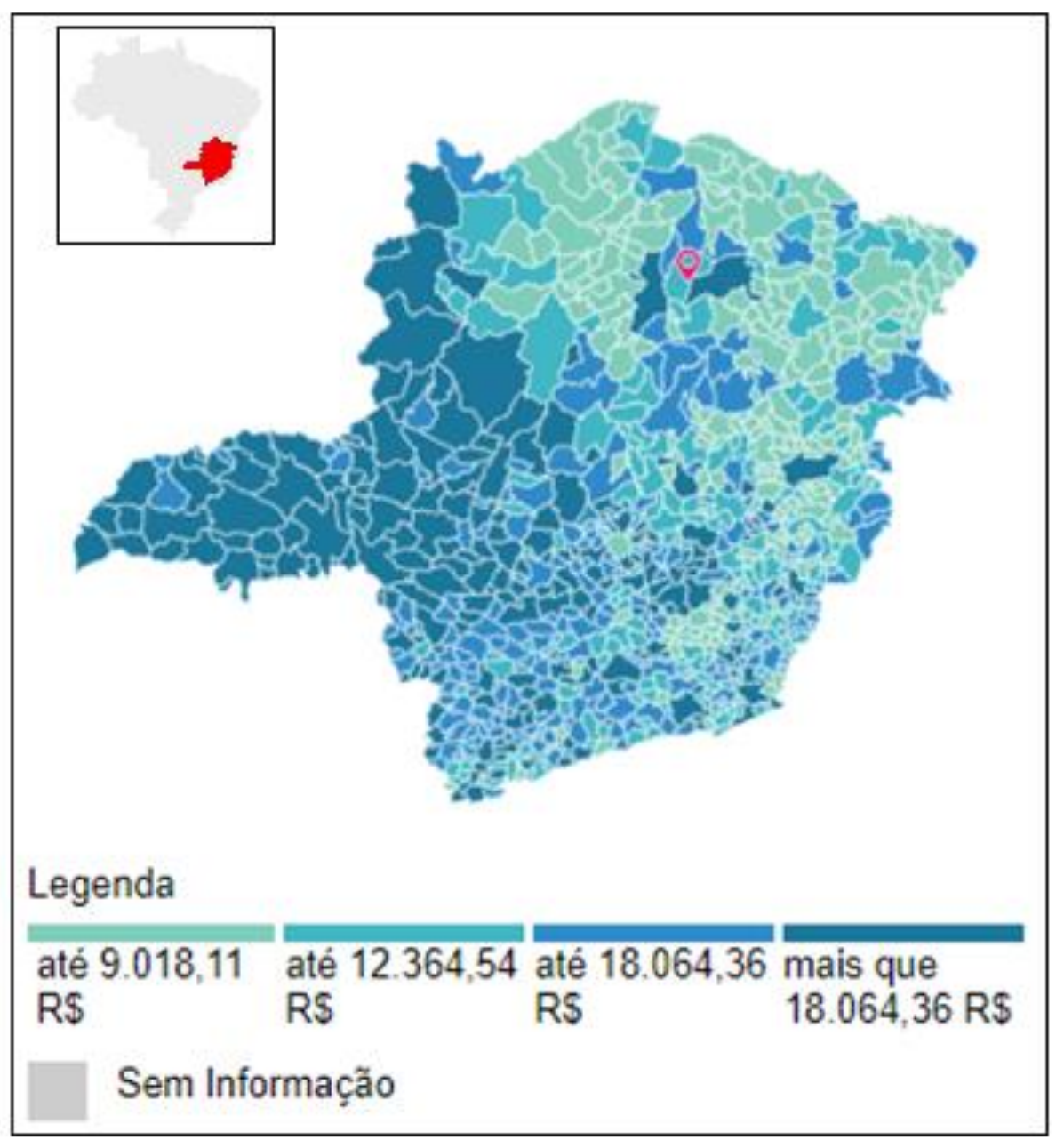

Fonte: IBGE/Cidades (2017). https://cidades.ibge.gov.br/brasil/mg/francisco-sa/panorama.

Note-se, no mapa (figura 2), a diferença de renda entre o norte e o sul de Minas, com o município de Francisco Sá destacado em vermelho (IBGE, 2017).

É interessante situar alguns dados da situação socioeconômica do município no momento em que Drummond escreve seu segundo livro. Dados do censo de 1940 mostram o município de Francisco Sá com 1.257 estabelecimentos agropecuários, perfazendo uma área de 298.102 hectares e com valor total de Cr\$15.111.000. Em relação aos estabelecimentos industriais, o município conta em 1940 com apenas 2, que realizam capital de Cr\$5.000 e empregam somente 9 pessoas. O censo também mostra que, àquele momento, Francisco Sá possuía altíssima porcentagem de analfabetismo, 71,98\% (IBGE, 1940, p. 206) - como Brejo das Almas só foi desmembrado de Montes Claros em 1923 e o censo de 1930 não ocorreu, não existem dados populacionais anteriores a 1940 .

À epigrafe do livro, encontramos uma apresentação bastante lúgubre do município, mas que destaca sua "especialidade" econômica e um de seus momentos de prosperidade:

\footnotetext{
Brejo das Almas é um dos municípios mineiros onde os cereais são cultivados em maior escala. Sua exportação é feita para os mercados de Montes Claros e Belo Horizonte. Há também grande exportação de toucinho, mamona e ovos. A lavoura de cana-deaçucar tem se desenvolvido bastante. Ultimamente, cogita-se da mudança do nome do município, que está cada vez. mais próspero. Não se compreende mesmo que fique toda a vida com o primitivo: Brejo das Almas, que nada significa e nenbuma justificativa oferece. D'A Pátria, 6-VIII-1931 (Andrade, 2013, p. 9).
} 
Interessante notar a vocação agropecuária do município: cereais, mamona, ovos, toucinho e cana-de-açúcar. Note-se que, somente em 1938, portanto no momento da mudança do nome Brejo das Almas para Francisco Sá, instituiu-se o DecretoLei $n^{\circ} 311$, segundo o qual "a sede do município tem a categoria de cidade e lhe dá o nome" (Azevedo, 1992, p. 24). Mesmo assim, em 1950, aproximadamente duas décadas após a publicação de "Brejo das Almas", o Brasil conta "apenas" 1890 cidades (se comparadas com as mais de 5 mil encontradas seis décadas mais tarde), das quais 1453 com menos de 5 mil habitantes. Para Azevedo (1992, p. 24):

Evidentemente, seria um erro afirmar que esses 1890 centros urbanos devem ser considerados verdadeiras cidades, de acordo com o conceito geográfico desta palavra, pois a grande maioria não apresenta as características culturais e sociais, a estrutura, as características demográficas e as funções geralmente apontadas pelos geógrafos para que possam ser como tais classificados. Acreditamos estar mais próximos da realidade se tomarmos como limite minimo para a conceituação das cidades (na falta de outro critério) a população urbana de 10.000 hab. Nesta hipótese, existiriam, em 1950, apenas 204 aglomerados urbanos que mereceriam aquela designação, no ponto de vista da Geografia.

Dessas 204, somente 35, ou seja, 17\%, encontravam-se no estado de Minas Gerais. O censo decenal de 1930 não ocorreu no Brasil, por motivos "principalmente de ordem política" (IBGE, 2003, p. 18). Pelo censo de 1940 , entretanto, o primeiro realizado pelo Instituto Brasileiro de Geografia e Estatística (IBGE), Francisco Sá já aparece com 23.419 habitantes (IBGE, 1940, p. 206), portanto atendendo ao critério fixado por Aroldo de Azevedo para receber a denominação de "cidade".

Outro dado interessante diz respeito à área territorial. Pelo Censo de 1940, a área da capital do estado, Belo Horizonte, é de $222 \mathrm{~km}^{2}$, e de Francisco Sá, de $5.066 \mathrm{~km}^{2}$, ou seja, 22 vezes maior - essa discrepância territorial, ao lado da epígrafe do livro de Drummond, permite supor que a área municipal é composta por grande extensão rural associada a um pequeno núcleo urbano com funções administrativas e comerciais incipientes. Estas são as características geográficas principais da pequena cidade que nomeia o segundo livro de poesias de Carlos Drummond de Andrade.

\section{Brejo das Almas: o livro}

Há relativa controvérsia na crítica literária na caracterização desta obra e sua posição na poética drummondiana. A principal linhagem crítica parte de António Cândido, para quem "Alguma Poesia" e "Brejo das Almas" são obras construídas "em torno de um certo reconhecimento do fato" e onde:

O sentimento, os acontecimentos, o espetáculo material e espiritual do mundo são tratados como se o poeta se limitasse a registrá-los, embora o faça da maneira anticonvencional preconizada pelo Modernismo. Este tratamento, mesmo quando insólito, garantiria a validade do fato como objeto poético bastante em si, nivelando fraternalmente 0 Eu e o mundo como assuntos de poesia (Cândido, 2011, p. 69).

Vagner Camilo, por outro lado, se contrapõe a essa associação entre a obra de estreia e o livro subsequente, situando o segundo na esteira da crise de 1930, que envolve "a pressão experimentada pelo poeta em virtude de sua indecisão ideológica, justamente num momento em que se verificava a inserção política cada vez maior de nomes representativos do grupo modernista" (Camilo, 2000, p. 38). Essa interpretação tem origem na obra de John Gledson, "Poesia e poética de Carlos Drummond de Andrade", e encontra prova de sua pertinência nas palavras do próprio poeta, em entrevista de 1931, concedida ao jornal "A Pátria" (jornal que parece ser a origem, por sinal, da epígrafe do livro de 1934):

Espiritualmente, a minha geração está diante de três rumos, ou de trếs soluções - Deus, Freud e o comunismo. A bem dizer, os rumos são dois apenas: uma ação católica, fascista e organizada em "Defesa do Ocidente" de um lado; do outro o paraíso moscovita, com a sua terrivel e, por isso mesmo, envolvente sedução. Que é um apelo a tudo quanto subsiste em nós de romântico $e$ descontrolado. Mas entre as duas posições, que impõem duas disciplinas, há lugar para a simples investigação cientifica, que nos fornece a chave, e por assim dizer o perdão dos nossos erros mais intimos e das nossas mais dolorosas perplexidades. "V amos todos para a Pasárgada” é o grito que o crítico Mário de Andrade ouviu de quase todas as nossas bocas, e creio que ouviu bem... Aqueles a quem o tomismo não consola e o plano quinquenal não interessa, esses se voltam para a libertação do instinto, o supra-realismo e a explicação dos sonhos, 
no roteiro da psicanálise. Ao ceticismo, à disponibilidade, à não-opção sucede - nova moléstia do espírito - essa "ida a Pasárgada", paraíso freudiano, onde o poeta Manuel Bandeira afirma que tem "a mulher que en quero, na cama que escolherei", além de muitas outras utilidades que correspondem à satisfação de muitos outros impulsos sequestrados. Quanto à minha atitude pessoal diante desses três rumos possivieis, creio que não interessa aos leitores de A Pátriavi (Gledson, 1981, pp. 90-91; Camilo, 2000, pp. 38-39).

Temos, aqui, um claro testemunho existencial, que se contrapõe à interpretação usual segundo a qual a fase poética de "Brejo das Almas" é presidida pelo fato e seu registro. O poeta mostra uma consciência aguda dos dilemas existenciais de sua geração e revela o seu próprio mal-estar diante das “opções de libertação" que lhe são apresentadas, às quais responde com seu peculiar ceticismo crítico.

Estamos, assim, diante de um livro que faz referência clara a uma cidade objetiva, específica e peculiar do interior de Minas, pequena, pouco desenvolvida e de urbanização incipiente, de imenso território para seus pouco mais de 20 mil habitantes, que "exporta" toucinho, mamona e ovos, e mergulha na pujança da cana-de-açúcar. Mas ela parece representar, antes, um “alter ego" da alma em crise, descendo ao lodo do brejo. O nome da cidade é sombrio e sugestivo dessa crise, e sua escolha como título não é ocasional, interpretação que se consolida na leitura dos poemas, de inconteste tonalidade melancólica, como veremos a seguir.

\section{Sim: ao eterno}

O terreno poético de "Brejo das Almas" é inquestionavelmente pantanoso e as páginas do livro estão tingidas de melancolia. A vida cotidiana é uma presença importante, mas está longe de se restringir ao fato e é permeada de vigor crítico, embora muitos dos poemas da obra tenham tonalidade mais emotiva que contestatória. A voz lírica está tomada por desencanto, mas o recurso à ironia, ao sarcasmo e ao humor também está presente como método de dissolução de tensões e exercício (auto)crítico. Esse misto de melancolia, desespero, ironia e humor, liricamente explosivo e produtor de poesia maior, é cristalizado pelo poema "Não se mate", da parte final do livro, em que o suicídio, mais que uma referência, é uma verdadeira hipótese:

Carlos, sossegue, o amor é isso que você está vendo: boje beija, amanhã não beija, depois de amanhã é domingo e segunda-feira ninguém sabe o que será.

Inútil você resistir ou mesmo suicidar-se. Não se mate, ob não se mate, reserve-se todo para as bodas que ninguém sabe quando virão, se é que virão.

O amor, Carlos, você telúrico, a noite passou em você, $e$ os recalques se sublimando, lá dentro um barulho inefável, rezas, vitrolas, santos que se persignam, anúncios do melhor sabão, barulho que ninguém sabe de quê, pra quê.

Entretanto você caminha melancólico e vertical. Você é a palmeira, você é o grito que ninguém ouviu no teatro $e$ as luzes todas se apagam. O amor no escuro, não, no claro, é sempre triste, meu filho, Carlos, mas não diga nada a ninguém, ninguém sabe nem saberá.

(Andrade, 2013, pp. 35-36).

Nota-se, aqui, a presença do tema da fragilidade das relações, exposto sobretudo na caracterização do amor, na primeira estrofe: "O amor / é isso que você está vendo: / hoje beija, amanhã não beija, / depois de amanhã é domingo / e segunda-feira ninguém sabe / o que será". É interessante observar, também, a presença de uma terminologia psicanalítica, na terceira estrofe: "a noite passou em você, / e os recalques se sublimando", que ecoam algo das palavras do poeta na entrevista à revista "A pátria", em 1931, na passagem em que afirma que, espiritualmente, a sua "geração está diante de três rumos, ou de três soluções - Deus, Freud e o comunismo". Este poema, construído através do monólogo interior e de forte tonalidade confessional, parece apontar para o rumo da segunda "solução". Simultaneamente, há um tom cético que perpassa a 
maioria dos versos e não nos deixa acreditar que o poeta toma esse rumo como verdadeira e duradoura solução para seus dilemas existenciais e seu malestar frente ao mundo e frente à história.

Camilo (2000, p. 39) deixa claro que essa terminologia permeia diversos momentos de "Brejo das Almas", mas lê na entrevista acima mencionada "a não-pactuação com qualquer das três soluções", ou seja, a opção pelo ceticismo, marca muito forte do poema "Não se mate". A esperança, de fato, está ausente de "Brejo das Almas", ausência indicada pelo tom cético que atravessa todo o livro e cristalizada no célebre poema "Soneto da perdida esperança":

Perdi o bonde e a esperança.
Volto pálido para casa.
A rua é inútil e nenhum auto
passaria sobre meu corpo.
Vou subir a ladeira lenta
em que os caminhos se fundem.
Todos eles conduzem ao
princípio do drama e da flora.
Não sei se estou sofrendo
ou se é alguém que se diverte
por que não? na noite escassa

com um insolúvel flautim. Entretanto há muito tempo nós gritamos: sim! ao eterno.

(Andrade, 2013, p. 14).

É importante destacar, aqui, a forte imbricação entre o tema da desesperança e a vida urbana marcada no cotidiano e no aparelhamento da cidade. A esperança é retratada como elemento muito frágil, capaz de se estilhaçar diante da mais insignificante perda, que parte de um acontecimento corriqueiro para o habitante da cidade: "Perdi o bonde e a esperança". A rua encarna esse vazio, "é inútil" e, nela, "nenhum auto / passaria sobre o meu corpo". A cidade se revela como espaço do existir, onde a dimensão factual é elemento constitutivo da dimensão simbólica: o bonde (objetividade) é condição da esperança (subjetividade); a rua (objetividade) corporifica o desespero (subjetividade): "o urbano é devir objetivo, subjetivo, emocional e, sobretudo, histórico" (Scarlato \& Costa, 2017, p. 13). Sujeito-corpo e sujeito-sentimento (Lindón, 2009) se entrelaçam nas ruas da pequena cidade mineira.
Também é necessário destacar a força e o significado lírico dos versos finais do poema: "Entretanto há muito tempo / nós gritamos: sim! Ao eterno". O eu lírico grita "sim" ao eterno, contrapondo-se à fugacidade dos eventos e à fragilidade da esperança. Este eterno pode representar a conciliação entre os espaços objetivo e subjetivo que se concretizam numa cidade melancólica, onde "tudo que é sólido desmancha no ar" (Berman, 2007), e de onde se almeja um outro futuro. Aqui destaca-se a delicada questão da perenidade e do efêmero. A poesia - na realidade, a arte como um todo - é uma das formas através das quais o sujeito diz sim ao eterno, ao perene, ao duradouro. É uma das formas através das quais o sujeito procura reagir à fragilidade das emoções, das relações, dos eventos - mesmo que, na modernidade, ela se realize por meio da dissolução da estrutura e pela aceitação da fragmentação do verso, ela é ainda forma criada que ultrapassa a fragilidade do sujeito e a ele sobrevive, dando sentido a emoções e semeando ou sedimentando concepções de mundo envolvidas num processo de criação que, necessariamente, dá voz e forma a um inconsciente coletivo.

Neste sentido, ao analisar a poética de Valéry, no ensaio "O artista como representante", Adorno (2003, p. 155) observa que: "O paradoxo em torno do qual se organiza" sua obra "é precisamente o de que o homem como um todo, e toda a humanidade, estão presentes em cada expressão artística" e "essa intenção só pode ser efetivada por meio de uma divisão do trabalho esquecida de si mesma e intensificada até o sacrifício da individualidade, até a capitulação de cada homem em particular". Desta forma, "O artista, portador da obra de arte, não é apenas aquele indivíduo que a produz, mas sim torna-se o representante, por meio de seu trabalho e de sua passiva atividade, do sujeito social coletivo" (Adorno, 2003, p. 164). E este sujeito social coletivo é, na modernidade, cada vez mais urbano.

O paradoxo desse sujeito social coletivo é que sua voz ressalta primordialmente a incomunicabilidade, causa e consequência da desesperança histórica. A incomunicabilidade contribui para fragmentar e alienar, mas também representa uma busca pelo outro: "O ser humano tem emoções, percepções que lhe permitem a construção de representações simbólicas garantidoras da busca do outro; caso contrário, teríamos um mundo de plena solidão" (Scarlato \& Costa, 2017, p. 5). Há uma "plena solidão" se revelando nos versos de Drummond e partindo das 
ruas melancólicas da cidade, há um distanciamento, uma fragmentação, mas há também a manifestação constante da insatisfação do sujeito diante das carências emocionais, que tornam até a poesia incomunicável:

A poesia é incomunicável. Fique torto no seu canto. Não ame.

Ouco dizer que há tiroteio ao alcance do nosso corpo. É a revolução? o amor? Não diga nada.

Tudo épossível, só eu impossivel.

O mar transborda de peixes. Há homens que andam no mar como se andassem na rua. Não conte.

Suponha que um anjo de fogo varresse a face da terra e os homens sacrificados pedissem perdão. Não peça.

(Andrade, 2013, p. 39).

Aqui, a poesia não é tomada como força de positivação da realidade precária, com vistas a suplantar, de forma idealística, as carências e insuficiências do real que se manifestam nas ruas da pequena cidade melancólica. Revela, antes, uma experiência existencial sensível que antecede e ultrapassa a linguagem enquanto objetivação, usando o real para apontar as carências e insuficiências da linguagem, num jogo de reflexão contraditória entre as dimensões objetiva e subjetiva da existência. Também revela um arraigado "pessimismo da modernidade" ao associar a desesperança a elementos típicos do momento histórico, como a contenda política e as aspirações de transformação contidas, por exemplo, na segunda estrofe.

Esse "pessimismo da modernidade" tem como um de seus corolários a embriaguez, elemento importante na obra dos "poetas malditos" do século XIX. É célebre, por exemplo, o verso de Baudelaire, em seu famoso poema "Embriaguem-se", de "O esplim de Paris": "É preciso estarem sempre embriagados" (Baudelaire, 2010, p. 96). Em "Brejo das Almas", a embriaguez reforça o sentimento de vazio da alma depauperada, que vive onde "Tudo era irreparável", verso do poema "Aurora", que abre o livro com essa carga sensível claramente articulada à vida cotidiana:

O poeta ia bêbedo no bonde. $O$ dia nascia atrás dos quintais. As pensões alegres dormiam tristissimas. As casas também iam bêbedas.

Tudo era irreparável. Ninguém sabia que o mundo ia acabar (apenas uma criança percebeu mas ficou calada), que o mundo ia acabar às 7 e 45. Últimos pensamentos! últimos telegramas! José, que colocava pronomes, Helena, que amava os homens, Sebastião, que se arruinava, Artur, que não dizia nada, embarcam para a eternidade.

O poeta está bêbedo, mas escuta um apelo na aurora: $V$ amos todos dançar entre o bonde e a árvore?

Entre o bonde e a árvore dançai, meus irmãos! Embora sem música dançai, meus irmãos! Os filhos estão nascendo com tamanha espontaneidade. Como é maravilhoso o amor (o amor e outros produtos).

Dançai, meus irmãos! A morte virá depois como um sacramento.

(Andrade, 2013, p. 11).

O ambiente urbano é claramente situado já à primeira estrofe. Será Brejo das Almas? Itabira? Ou alguma outra cidade do poema "Lanterna Mágica"? Há elementos comuns: o bonde, os quintais, as pensões. O bonde, por sua vez, é o elemento inicial, como ocorre no "Soneto da Perdida Esperança". Nota-se também a presença de uma figura de linguagem recorrente na poesia de Drummond, a prosopopeia: as pensões dormem; as casas estão bêbedas, um verdadeiro processo de fusão ser-espaço, objetividade-subjetividade, por meio da linguagem. Esta é uma forma de olhar para o espaço e de traduzir a cidade da existência, a cidade que é mais que seus objetos.

Este poema exibe um forte conteúdo crítico, que já se aproxima da crítica radical que será 
a tônica de muitos versos de "Sentimento do Mundo" e, sobretudo, "A rosa do povo", os livros do início da década de 1940 conhecidos pelo seu forte conteúdo político. Esse conteúdo crítico se depreende sobretudo da caracterização do amor como produto, na última estrofe, que recorre à ironia cáustica: "Os filhos estão nascendo / com tamanha espontaneidade. / Como é maravilhoso o amor / (o amor e outros produtos)". Assim, as relações sociais, que encontram no amor a sua mais sensível e significativa manifestação, se mercantilizam, reforçando a fragmentação e a incomunicabilidade.

Esses poemas evidenciam a busca interior pelo duradouro, pelo perene, pelo sólido, pelo adensamento das relações, e escancaram a frustração de um sujeito obrigado a contentar-se com o fugaz, com a fragmentação e a incomunicabilidade. E os elementos urbanos compõem claramente o quadro existencial negativo em que se anseia pelo eterno e vive-se com o efêmero.

\section{A cidade atravessa o sujeito}

Esse anseio pelo eterno parece fazer do amor o tema mais recorrente do livro "Brejo das Almas". O amor é o tema principal dos poemas "Boca", "O amor bate na aorta", "O passarinho dela", "Poema patético", "As namoradas mineiras", "O procurador do amor", "Necrológio dos desiludidos do amor", "Oceania" e "Desdobramento de Adalgisa"; e é tema secundário, mas significativo, nos poemas "Aurora", "Registro Civil", "Sol de vidro", "Um homem e seu carnaval", "Em face dos últimos acontecimentos", "Girassol", "Não se mate", "Canção para ninar mulher" e "Sombra das moças em flor". Dezoito poemas que totalizam $70 \%$ da obra.

Ora o tema retrata a fragilidade dos laços, como em "As namoradas mineiras" e no já analisado "Não se mate"; ora reforça a incomunicabilidade, o isolamento e a desilusão, como em "Boca": "Boca: nunca te beijarei. / Boca de outro, que ris de mim, / no milímetro que nos separa, / cabem todos os abismos" (Andrade, 2013, p. 13); ou em "O amor bate na aorta", que é a "Cantiga do amor sem eira / nem beira", que "vira o mundo de cabeça / para baixo" e "se estrepa" ao cair do alto de uma árvore, deixando "o sangue / que escorre do corpo andrógino" e uma ferida que "às vezes não sara nunca / às vezes sara amanhã" (Andrade, 2013, pp. 17-18); ou ainda em "Poema patético": "Que barulho é esse na escada? / É o amor que está acabando, / É o homem que fechou a porta / e se enforcou na cortina" (Andrade, 2013, p. 22).

Por vezes, o tema também parece constituir um imperativo que induz o sujeito a um estado de sofrimento compulsório, do qual é impossível libertar-se (daí, também, a recorrência do tema do suicídio na obra, envolvendo um eu lírico que se apresenta frequentemente no limite de suas forças, propenso aos comportamentos drásticos e às decisões impulsivas): "Amor, a quanto me obrigas. / De dorso curvo e olhar aceso, / troto as avenidas neutras / atrás da sombra que me inculcas" - em "O procurador do amor" (Andrade, 2013, p. 29); “Amo burra, burramente / certa menina enfezada / para lá dos mares do sul. / Ela vem por sobre as ondas / enfeitiçar minha vida, / atrapalhar minha mesa, / dizer que espere... esperarei" - em "Oceania" (Andrade, 2013, p. 42).

Nessa desilusão e nesse imperativo que pesam sobre as relações românticas, inserindo-as no estado geral de tensão e melancolia do sujeito, a mulher é uma presença marcante, que leva o eu lírico a expor sem muito pudor seus instintos mais primitivos. Villaça (2013, p. 50) observa, neste sentido, que:

Não há dúvida: a mulher é presença central na
maior parte dos poemas, surgindo como fêmea
devoradora, múltipla, satânica, submetendo o
homem a várias formas de aniquilamento, que vão
da paralisia à dissolução pornográfica, da luxúria
ao chamamento do suicídio. No limite, o
desmoronamento e a perdição do sujeito constituem
uma espécie de apocalipse pessoal, à luz última de
Sodoma, "que o anjo soprou” (...). Impõe-se a
pressão da culpa moral, em meio à submissão aos
instintos. A ironia se acirra e avança para o
sarcasmo, as zonas mais sombrias do espirito
ameaçam recobrir o indivíduo por inteiro. (...)
Como que extravasando os limites do indivíduo,
essa linguagem corrosiva dispõe-se ao aliciamento do
outro, do leitor, pelos "convites tristes”, pelos
imperativos dramáticos, pelas prevenções
sarcásticas.

A presença da cidade, na obra, obedece assim mais aos ritmos emocionais e efusivos da subjetividade desesperada. Ela é, neste sentido, uma presença concreta, revelando as angústias de uma existência que se corporifica na cidade, mas não é uma presença objetiva, e ainda menos "objetivista". As cidades, por isso, são pouco nomeadas - Brejo das Almas, por exemplo, só aparece no título: são trazidas à expressão lírica mais pelos traços comuns 
e pelo interesse interior ao sofrimento existencial que por características imanentes e específicas.

Podemos dizer, desta forma, que, em "Brejo das Almas", a cidade, subsumida nos temas do amor impossível, da comunicação inútil e da subjetividade estilhaçada, atravessa o sujeito, chegando a tornar-se uma espécie de "contingência da alma”. É o que ocorre, por exemplo, no poema "As namoradas mineiras":

Uma namorada em cada municipio, os municípios mineiros são duzentos e quinze, mas o verdadeiro amor onde se esconderá: em Varginha, Espinosa ou Caratinga?

Estradas de ferro distribuem a correspondência, a esperança é verde como os telegramas, uma carta para cada uma das namoradas $e o$ amor vence a divisão administrativa.

Para Teófilo Otoni o beijo vai por via aérea, os carinhos do sul pulam sobre a Mantiqueira, mas as melhores, mais doces namoradas são as de Santo Antônio do Monte e Santa Rita.

No Oeste, na Mata, no Triângulo, no norte de Minas há saudades e ais. Suspiros sobem do vale do rio Doce e o rio São Francisco trança mágoas.

Enquanto na Capital um homem indiferente, frio, desdobrando mapas sobre a mesa, põe o amor escrevendo no mimeógrafo a mesma carta para todas as namoradas.

(Andrade, 2013, p. 27).

As cidades saltam, assim, diante dos olhos do leitor: duzentos e quinze municípios mineiros, Varginha, Espinosa, Caratinga, Teófilo Otoni, Santo Antônio do Monte, Santa Rita e a capital, Belo Horizonte. Porém, elas parecem dispersas, algo aleatórias e o eu lírico não se detém em nenhuma delas. A geografia parece, antes, um acessório destinado a reforçar a tese principal do poema, que orbita em torno da volatilidade do amor e da precariedade dos laços afetivos: um amor em cada cidade, "mas o verdadeiro amor onde se esconderá"? Drummond parece reforçar, neste poema, "A misteriosa fragilidade dos vínculos humanos, o sentimento de insegurança que ela inspira e os desejos conflitantes (estimulados por tal sentimento) de apertar os laços e ao mesmo tempo mantê-los frouxos" (Bauman, 2004, p. 8). Nessa negatividade crítica (que aqui está tingida por uma fina ironia), revela mais uma vez seu anseio pelo perene, pelo duradouro, pelo eterno, pelo outro.

A fragmentação urbana do poema, neste sentido, não revela superficialidade; ela é claramente um espelho da própria fragmentação do sujeito. Há, desta forma, um movimento de interiorização da cidade neste livro, de que a prosopopeia é uma das evidências. Podemos dizer que há momentos em que o sujeito atravessa a cidade, tentando lançar a ela um olhar de observador, um olhar estudioso, que ensaia um afastamento afetivo. Esta é a postura do crítico, que o poeta Drummond também assume, em sua obra em verso, de forma recorrente (evidentemente, com esta postura, ele também revela seus afetos, pois o distanciamento crítico absoluto é sempre uma quimera, e essa quimera também fala de anseios interiores, afetivos e emocionais). Há outros em que a cidade atravessa o sujeito, incorporando-se como substância da existência e como tal sendo representada na poesia. Neste caso, manifesta-se mais claramente uma voz da cidade através do sujeito. Este é precisamente o caso de "Brejo das Almas".

\section{A cidade fala através do homem}

Vemos claramente, no mapa do poema "Lanterna Mágica", que há certa coesão espacial em relação às cidades abordadas, com a proximidade de várias delas em relação a Belo Horizonte. Ao elaborar o mapa (fig. 3) do poema "As namoradas mineiras", pelo contrário, observamos uma clara dispersão $\mathrm{O}$ eu lírico vai do extremo norte, já no domínio morfoclimático do sertão mineiro, ao sul do estado. Vai da empobrecida Espinosa, com seu PIB per capita de R\$8.139,71, à pujante Varginha, onde o PPC chega a $\mathrm{R} \$ 34.827,43$, passando pela Capital, onde esse valor é um pouco mais elevado: $\mathrm{R} \$ 34.910,13$ (IBGE, 2017). Abaixo, na fig. 4, o PIB per capita de todas as cidades do poema, em dados de 2015, demonstrando clara discrepância entre as cidades do norte e do sul.

Para chegarmos mais perto da data de publicação da obra, é interessante analisar alguns dados socioeconômicos disponíveis no censo de 1940. Neste momento, Espinosa registra um número de 2.087 estabelecimentos agropecuários, com uma área de 112.694 ha e valor total de Cr\$ 8.179.000, enquanto Varginha conta com 473 estabelecimentos em 35.827 ha e valor de Cr\$ 27.287.000. A capital Belo Horizonte, por sua vez, tem 188 estabelecimentos em 10.424 ha e valor de 
Cr\$26.277.000 (IBGE, 1940, pp. 60-72), dados que já expõem uma forte discrepância econômica entre o norte e o sul mineiro.

Em relação aos dados industriais, as discrepâncias são ainda maiores: enquanto Belo Horizonte conta, em 1940, com 400 estabelecimentos industriais, que realizam um capital de Cr\$105.594.000 e empregam 12.816 pessoas, e Varginha com 67 estabelecimentos, realizando capital de Cr\$1.249.000 e empregando 432 trabalhadores, Espinosa conta apenas 5 estabelecimentos, que realizam um capital de Cr\$ 119.000 e empregam apenas 27 pessoas (IBGE, 1940, pp. 503-505).

Os dados de analfabetismo são ainda mais graves. Espinosa tem, em 1940, 13.919 habitantes, dos quais 10.076 não sabem ler nem escrever, um escandaloso índice de analfabetismo de 72,39\% (IBGE, 1940, p. 62), índice que é de 19,57\% em Belo Horizonte (IBGE, 1940, p. 52) e 48,24\% (ainda alto, mas menor que em Espinosa) em Varginha. A seguir (fig. 5), observa-se as taxas de analfabetismo de todas as cidades citadas no poema "As namoradas mineiras" e a comparação com as cidades mineiras do poema "Lanterna Mágica" (fig. 6).

Os gráficos corroboram, assim, a disjunção apresentada pelo mapa do poema "As namoradas mineiras", e a comparação com as cidades de "Lanterna Mágica" indica maior discrepância social entre as cidades de "Brejo das Almas".

Figura 3 - As cidades do poema “As namoradas mineiras" (1934), na ordem em que aparecem no poema

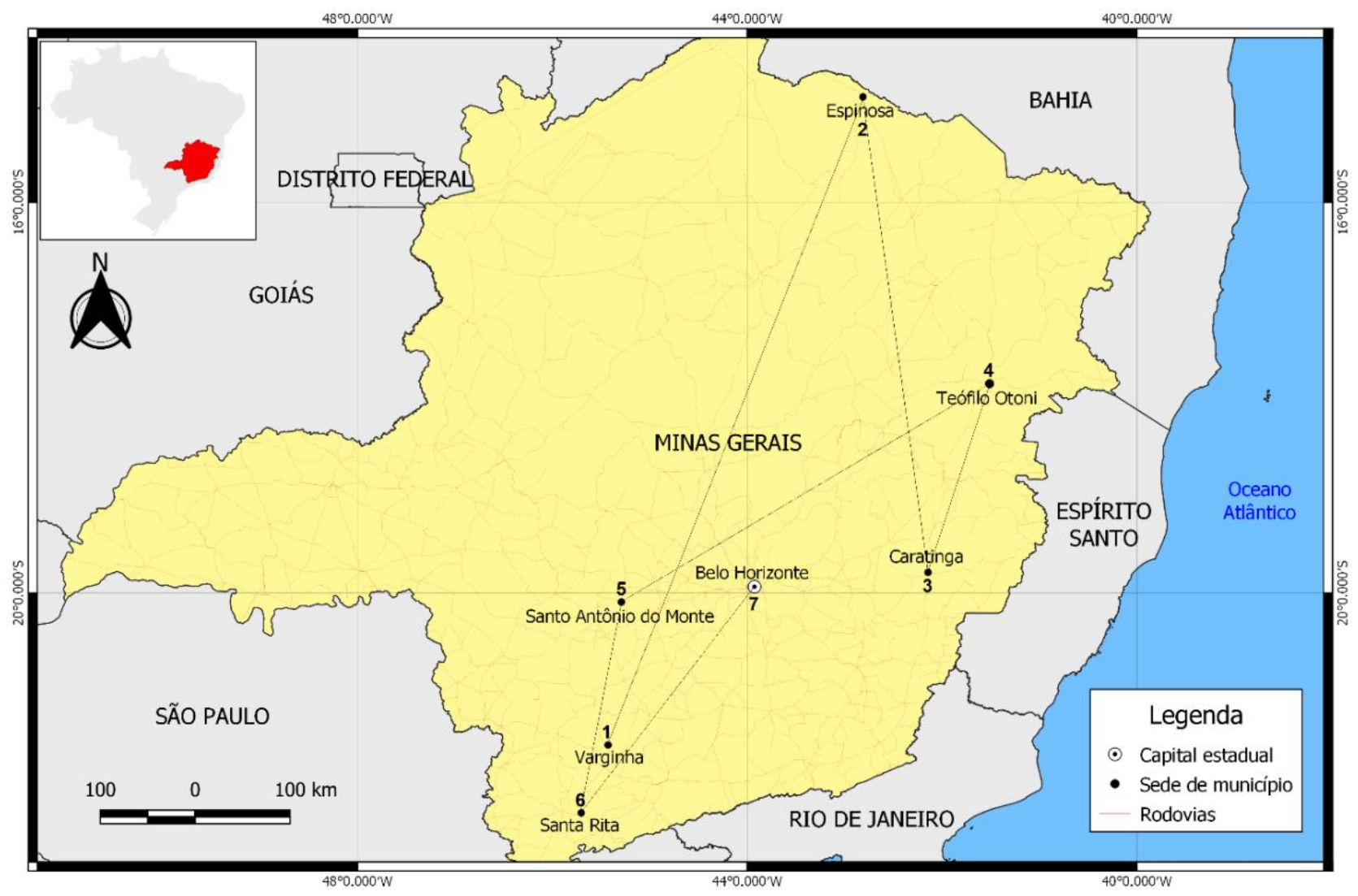

Fonte: elaboração própria, 2019, a partir de IBGE (2017)

e Sistema de Coordenadas Geográficas: Datum SIRGAS 2000. 
Figura 4 - Gráfico do PIB per capita de todas as cidades do poema, em dados de 2015

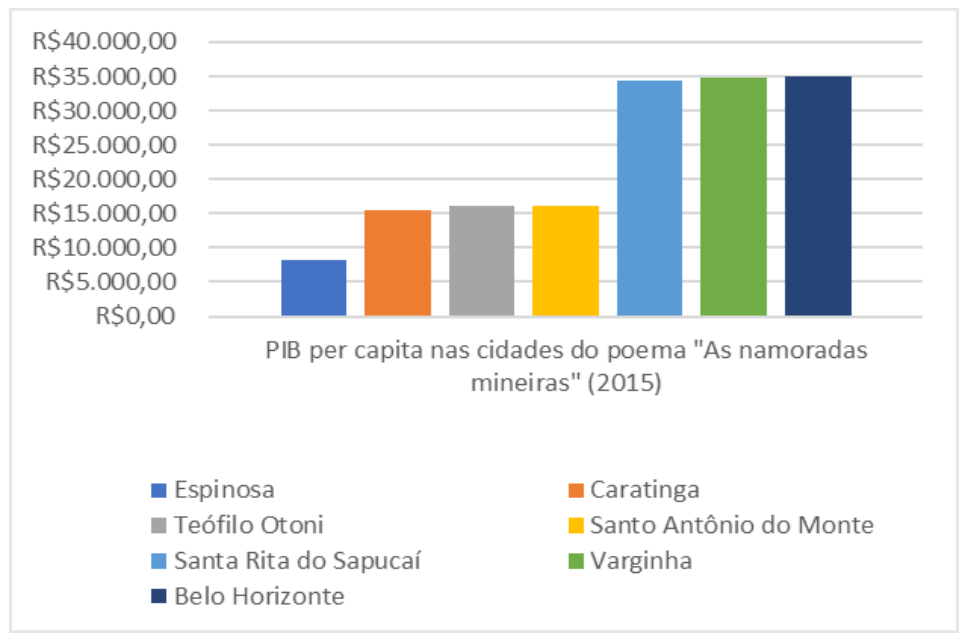

Fonte: elaboração própria, 2018, a partir de IBGE (2017).

Figura 5 - Gráfico das taxas de analfabetismo de todas as cidades citadas no poema "As namoradas mineiras"

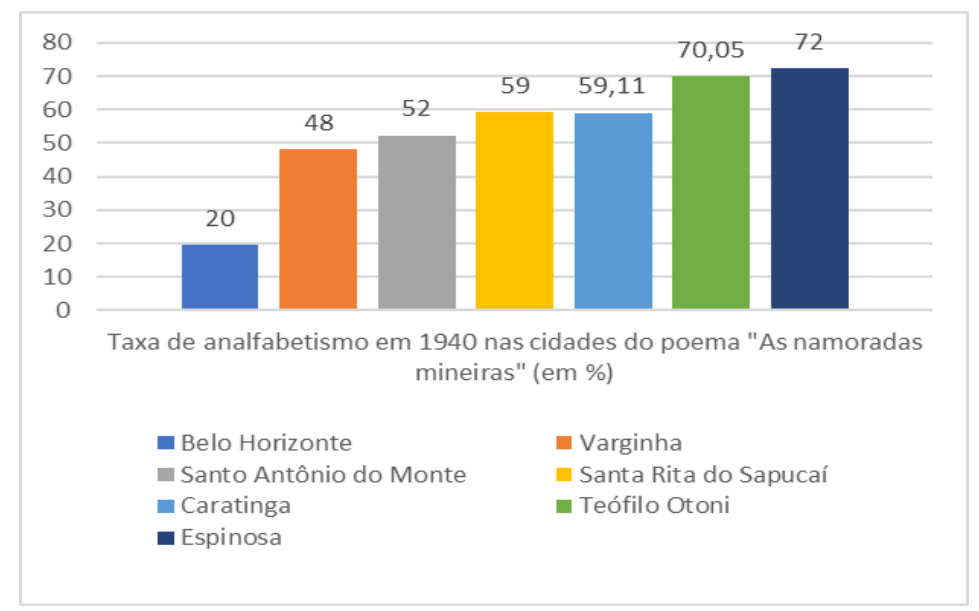

Fonte: elaboração própria, 2018, a partir de IBGE (1940).

Figura 6 - Gráfico de comparação com as cidades mineiras do poema "Lanterna Mágica"

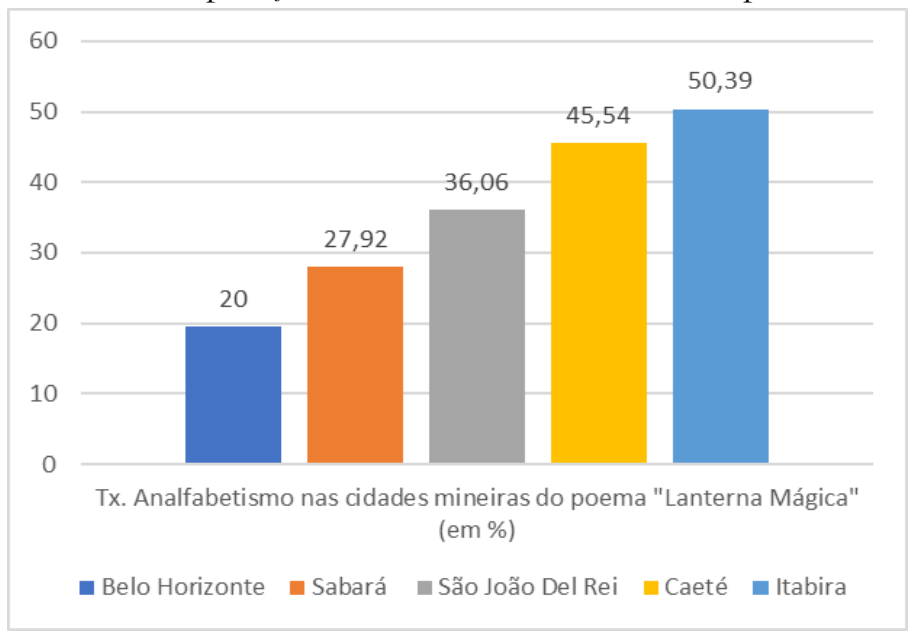

Fonte: Elaboração própria, 2018, a partir de IBGE (1940). 
Essa análise espacial ajuda a sedimentar, através do olhar e da linguagem da geografia, a visão de um sujeito em crise, propenso a tocar os extremos (sobretudo, os negativos) - da vida, do espaço, de Minas, da sociedade. A fragmentação das cidades é espelho da fragmentação subjetiva, uma prova da concreção das dimensões que são a essência da poesia e da cidade. A dispersão não é superficialidade: como mote para uma crítica às relações de amor na modernidade, indica novamente aspiração pelo perene, pelo adensamento da existência. A cidade atravessa o sujeito e por meio dela formalizam-se, na arte, as aspirações.

Há um outro poema, em "Brejo das Almas", que é oportuno para essa discussão, e que ecoa um dos mais célebres poemas de Baudelaire em "As flores do mal":

Aquele girassol no jardim público de Palmira. Ias de auto para Juiz de Fora; gasolina acabara; Havia um salão de barbeiro; um fotógrafo; uma igreja; um menino parado; Havia também (entre vários) um girassol. A moça passou.

Entre os seios e o girassol tua vontade ficou interdita.

Vontade garota de voar, de amar, de serfeliz, de viajar, de casar, de ter muitos filhos;

Vontade de tirar retrato com aquela moça, de praticar libidinagens, de ser infeliz. e rezar; Muitas vontades; a moça nem desconfiou... Entrou pela porta da igreja, saiu pela porta dos sonbos.

O girassol, estúpido, continuou a funcionar.

(Andrade, 2013, p. 32).

Este poema, que se aproxima do conto por sua forma narrativa prosaica, narra o evento de uma paixão fugaz, que se realiza enquanto promessa, por um par de segundos, para logo em seguida se "desmanchar no ar". Ela ocorre a um personagem (a quem o eu lírico se refere na segunda pessoa do singular, na forma arcaica, mas que parece estranhamente referir-se a ele mesmo, uma vez que formaliza um conjunto de desejos muito íntimos) que, em viagem a Juiz de Fora, é obrigado a parar em Palmira (hoje Santos Dumont, cidade localizada a aproximadamente $10 \mathrm{~km}$ de Juiz de Fora).

Nessa cidadezinha, onde havia apenas um salão de barbeiro, um fotógrafo e uma igreja, paisagem típica das pequenas cidades do interior de
Minas, se encanta por uma moça, que passa e se vai, sem desconfiar que causou "vontade de voar, de amar, de ser feliz, de viajar, de casar, de ter filhos, tirar retrato, praticar libidinagens, ser infeliz e rezar". Essa moça, que mobilizou tanta paixão, tanto desejo, entra então "pela porta da igreja" e sai "pela porta dos sonhos". Drummond parece, aqui, transpor ao ambiente de uma pequena cidade de Minas o evento que Baudelaire situa no alarido azafamado das ruas da metrópole:

La rue assourdissante autour de moi burlait. Longue, mince, en grand deuil, douleur majestueuse, Une femme passa, d' une main fastueuse Soulevant, balancant le feston et l'ourlet;

Agile et noble, avec sa jambe de stautue. Moi, je buvais, crispé comme un extravagant, Dans son oeil, ciel livide où germe l'ouragan, La douceur qui fascine et le plaisir qui tue.

Un éclair...puis la nuit! - Fugitive beauté Dont le regard m'a fait soudainement renaitre, Ne te verrai-je plus que dans l'eternité?

Ailleurs, bien loin d'ici! trop tard! "jamais" peutêtre! Carj'ignore où tu fuis, tu ne sais où je vais, Ô toi que j'eusse aimée, ô toi qui le savais! viii

(Baudelaire, 2006, p. 124).

Aqui, neste poema claramente situado no frenesi da cidade grande, no frenesi de Paris, temos uma relação de amor que se estabelece num fragmento de tempo, mas não ultrapassa o plano do puro platonismo, que não pode sequer perdurar, destruído pela fugacidade do ambiente e dos papéis assumidos por cada peça da engrenagem. $\mathrm{O}$ eu lírico de Baudelaire, como o de Drummond, deposita sua paixão numa transeunte que lhe encanta.

$\mathrm{O}$ amor, então, se realiza enquanto fragmento platônico e se desfaz irreversivelmente no próximo fragmento estilhaçado da vida moderna. A modernidade, assim, impressa no movimento da cidade, volta-se contra "os ideais de beleza, pureza e ordem" que, segundo Bauman (1998, p. 9), a edificam. Há, portanto, uma corrosão da sensibilidade, que se estilhaça em muitos fragmentos que se perdem com facilidade. O sujeito não alcança nem mesmo a realização dos desejos, fugazes e intermitentes por natureza. Como alcançaria a perenidade das relações? 
Mesmo, porém, que o eu lírico itabirano de Drummond possa encontrar-se com o eu lírico parisiense de Baudelaire, e mesmo que ambos compartilhem angústias que, ainda que universais, são mais evidentes nas relações sociais de uma grande metrópole, onde os laços sociais se deterioram de forma mais flagrante, parece evidente que a tonalidade afetiva de "Brejo das Almas", o livro, referindo-mais à condição da alma que às especificidades de Francisco Sá, falando através de um sujeito solitário, depauperado, cercado pelo tédio e flertando com a morte, nos remete à situação geográfica de uma pequena cidade provinciana, empobrecida, economicamente dependente do setor primário, de alta taxa de analfabetismo e estrutura técnica precária. Há nesses traços urbanos as marcas de uma angústia que o eu lírico reverbera em sua voz.

Devemos destacar, assim, esse enorme feito geo-literário: caracterizar a cidade de Brejo das Almas, que reflete a imagem de muitas cidadezinhas do interior de Minas, sem nomeá-la. Não há menção específica ao nome do município no decorrer do livro, fato que subsidia a interpretação de que o título da obra se refere mais à condição da alma que à caracterização da cidade. Referindo-se, no entanto, mais à alma que à cidade, expressa uma alma atravessada pela cidade e, assim, novamente por meio da fusão ser-espaço que se evidencia na figura da prosopopeia, Drummond acaba por caracterizar a cidade. A cidade fala através do homem.

\section{Considerações Finais}

Este artigo procurou discutir as relações entre geografia e literatura a partir da obra de um importante poeta brasileiro, Carlos Drummond de Andrade, reconhecido por seu mais célebre crítico, António Cândido, como um grande "poeta social" (Cândido, 2011, p. 85), um poeta moderno que produziu obra intensamente politizada e com insistentes marcas geográficas, construídas sobretudo na vivência do interior de Minas, na vivência de um itabirano "triste, orgulhoso, de ferro", como nos diz em sua "Confidência do Itabirano", em 1940.

É importante destacar a riqueza da poesia moderna para pensar o tema da cidade. Se Drummond está distante no tempo e no espaço de Baudelaire, o poeta que define "a ordem do dia para um século inteiro de arte e pensamento" (Berman, 2007, p. 159) e faz da modernidade "tema de acusação" (Adorno, 2003, p. 75), não deixa de expressar uma experiência da modernidade, que revela no interior de Minas a força de suas contradições, onde o moderno e o arcaico coabitam. O moderno, frequentemente povoando as volições, os devaneios, as frustrações do autor, ou marcado em relações sociais fragmentárias e fragmentadas; o arcaico, aqui entendido como o antigo, o passado, marcado em paisagens sociais que parecem resistir ao avanço das forças da modernidade.

Brejo das Almas é, desta forma, mote de uma expressão da alma tanto quanto da cidade. E de uma expressão da alma que se faz por meio da expressão da cidade. Ao caracterizar a alma, Drummond expressa a cidade; ao caracterizar a cidade, expressa a alma. Por isso a prosopopeia é uma figura de linguagem tão importante em sua poesia: por meio dela, o espaço se torna "ser", sente, fala, expressa, resiste, corporifica-se (ver poema "Carta a Stalingrado", de "A rosa do povo"). Assim, se revela na poesia "a essência do urbano vinculada ao existir espacialmente" (Scarlato \& Costa, 2017, p. 14).

Drummond pode ser entendido, assim, do ponto de vista da geografia, como um "poeta visceral", que capta com sua sensibilidade o espaço como dimensão da alma. Tanto a geografia do interior de Minas quanto das metrópoles que o poeta vivencia (Belo Horizonte e Rio de Janeiro, esta sobretudo na fase posterior à "Brejo das Almas", a fase política do início da década de 1940) ganham, assim, conotação universal, conectando-se às grandes questões existenciais da modernidade. $\mathrm{O}$ contato com o livro "Brejo das Almas", desta forma, aponta a riqueza que pode alcançar a poética da cidade na obra de Carlos Drummond de Andrade e sua importância para o olhar da geografia sobre a questão urbana e o interior mineiro.

\section{Referências bibliográficas}

Adorno, T. (2003). Notas de literatura I. São Paulo: Duas Cidades/Editora 34.

Andrade, C. (2002). Alguma Poesia. Rio de Janeiro: Record.

Andrade, C. (2013). Brejo das Almas. São Paulo: Companhia das Letras.

Azevedo, A. (1992). Vilas e cidades do Brasil colonial: ensaio de geografia urbana retrospectiva. Terra Livre, 10, 23-78. https://www.agb.org.br/publicacoes/index. $\mathrm{php} /$ terralivre/article/view/113/111

Baudelaire, B. (1985). As flores do mal. Rio de Janeiro: 
Nova Fronteira.

Baudelaire, B. (2006). Les fleurs du mal. Paris: Pocket.

Baudelaire, B. (2010). O esplim de Paris: pequenos poemas em prosa. São Paulo: Martin Claret.

Berman, M. (2007). Tudo que é sólido desmancha no ar: a aventura da modernidade. São Paulo: Companhia das Letras.

Bauman, Z. (1998). O mal-estar da pós-modernidade. Rio de Janeiro: Zahar.

Bauman, Z. (2004). Amor líquido: sobre a fragilidade dos laços humanos. Rio de Janeiro: Jorge Zahar.

Brosseau, M. (1996). Des romans géographes. Paris: L'harmattan.

Camilo, V. (2000). Uma poética da indecisão: Brejo das Almas. Novos Estudos CEBR AP, 57, 3758.

http://novosestudos.uol.com.br/produto/ edicao-57/

Cândido, A. (2011). Inquietudes na poesia de Drummond. In A. Candido. Vários Escritos (pp. 69-99). Rio de Janeiro: Ouro sobre Azul.

Corrêa, R. (1980). Da Nova Geografia à Geografia Nova. Revista de Cultura Vozes. Geografia e sociedade: os novos rumos do pensamento geográfico, 74(LXXIV), 5-12. Petrópolis: Vozes.

Gledson, J. (1981). Poesia e poética de Carlos Drummond de Andrade. São Paulo: Duas Cidades.

Instituto Brasileiro de Geografia e Estatística. (1940). Recenseamento Geral do Brasil $\left(1^{\circ}\right.$ de Setembro de 1940). Série Regional. Parte XIII: Minas Gerais. Tomo 2. https://biblioteca.ibge.gov.br/visualizacao/ periodicos/65/cd_1940_p13_t2_mg.pdf

Instituto Brasileiro de Geografia e Estatística. (2003). Metodologia do Censo Demográfico 2000. Rio de Janeiro: IBGE. https://biblioteca.ibge.gov.br/index.php/bi blioteca-catalogo?view $=$ detalhes\&id $=284173$

Instituto Brasileiro de Geografia e Estatística. (2017). IBGE Cidades. https://cidades.ibge.gov.br/

Lafaille, R. (1989). Départ: Géographie et poésie, The Canadian Geographer, 33(2), 118-130. https://doi.org/10.1111/j.15410064.1989.tb00893.x

Lévy, B. (2006). Geógraphie et littérature: une synthèse historique. Le Globe. Revue genevoise de géographie, 146, 25-52. https://www.persee.fr/doc/globe_03983412_2006_num_146_1_1513

Lévy, B. (1997). Géographie culturelle, géographie humaniste et littérature: Position épistémologique et méthodologique. Géographie et Cultures, 21, 27-44. https://www.researchgate.net/publication/2 94601485_Geographie_culturelle_geographi e_humaniste_et_litterature_Position_episte mologique_et_methodologique

Lindón, A. (2009). La construcción socioespacial de la ciudad: el sujeto cuerpo y el sujeto sentimiento. Revista Latinoamericana de Estudios sobre Cuerpos, Emociones y Sociedad, 1, 6-20.

http://www.relaces.com.ar/index.php/relac es/article/viewArticle/4

Marinho, S. (2010). Um homem, um lugar: geografia da vida e perspectiva ontológica. (Tese de Doutorado em Geografia). Universidade de São Paulo, São Paulo.

Scarlato, F. \& Costa, E. (2017). A natureza do urbano. Confins, 30. https://doi.org/10.4000/confins.11676

Villaça, A. (2013). Desejos tortos. In C. D. Andrade. Brejo das Almas (pp. 47-57). São Paulo: Companhia das Letras.

\section{Notas}

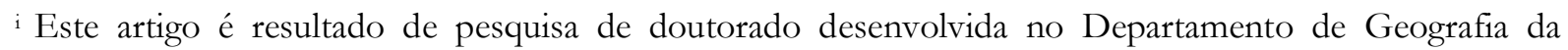
Universidade de São Paulo - FFLCH-DG-USP e financiada pelo Conselho Nacional de Desenvolvimento Científico e Tecnológico (CNPq).

ii Tradução própria.
} 
iii Tradução própria.
iv Tradução própria.
v Tradução própria.

vi Entrevista concedida por Carlos Drummond de Andrade ao jornal "A Pátria”, em 1931, e reproduzida por Gledson (1981, pp. 90-91) e Camilo (2000, pp. 38-39).

vii Figura de linguagem pela qual se emprestam sentimentos humanos e palavras a seres inanimados.

viii Tradução do poema "À une passante", de Baudelaire:

A rua em torno era um frenético alarido.

Toda de luto, alta e sutil, dor majestosa,

Uma mulher passou, com sua mão suntuosa

Erguendo e sacudindo a barra do vestido.

Pernas de estatua, era-lhe a imagem nobre e fina.

Qual bizarro basbaque, afoito en the bebia

No olhar, céu livido onde aflora a ventania,

A docura que envolve e o prazer que assassina.

Que luz... e a noite após! - Efêmera beldade

Cujos olhos me fazem nascer outra vez,

Não mais hei de te ver senão na eternidade?

Longe daqui! tarde demais! nunca talvez!

Pois de ti já me fui, de mim tu já fugiste,

Tu que eu teria amado, ó tu que bem o viste!

(Baudelaire, 1985, p. 345). 